\title{
Effect of double-hit deformation on the onset of critical stress for the initiation of dynamic transformation
}

\author{
kanwal chadha ${ }^{1}$, Clodualdo Aranas, $\mathrm{Jr}^{1}$, Zaid Ahmad ${ }^{2}$, Mohammad Jahazi ${ }^{3}$, and John \\ Spray $^{1}$
}

${ }^{1}$ University of New Brunswick Fredericton

${ }^{2}$ Regional Technological Institute University of West Bohemia

${ }^{3}$ École de technologie supérieure

May 5, 2020

\begin{abstract}
Double-hit hot compression tests were carried on medium-carbon low-alloy steels using Gleeble 3800@ thermomechanical simulator. The tests were performed at strain rates of 0.25 and $0.5 \mathrm{~s}-1$ and temperatures of 1150 and $1200{ }^{\circ} \mathrm{C}$ with an interpass time of $5 \mathrm{~s}$. The onset of critical stress for dynamic transformation (DT) were detected using the double-differentiation method. This metallurgical phenomenon was initiated under all testing conditions. The results show that the critical stress for DT increases with decrease in temperature and increase in strain rate.
\end{abstract}

\section{Hosted file}

Manuscript.pdf available at https://authorea.com/users/295795/articles/424931-effect-ofdouble-hit-deformation-on-the-onset-of-critical-stress-for-the-initiation-of-dynamictransformation

\section{Hosted file}

List of Tables.docx available at https://authorea.com/users/295795/articles/424931-effectof-double-hit-deformation-on-the-onset-of-critical-stress-for-the-initiation-of-dynamictransformation 